\title{
Transapical aortic valve implantation at 3 years
}

\author{
Thomas Walther, MD, PhD, ${ }^{\mathrm{a}}$ Jörg Kempfert, MD, ${ }^{\mathrm{a}}$ Ardawan Rastan, $\mathrm{MD}, \mathrm{PhD},{ }^{\mathrm{a}}$ Michael A. Borger, MD, PhD, ${ }^{\mathrm{a}}$ \\ Axel Linke, MD, PhD, Jörg Ender, MD, ${ }^{\mathrm{c}}$ Gerhard Schuler, MD, PhD, ${ }^{\mathrm{b}}$ and Friedrich W. Mohr, MD, PhD ${ }^{\mathrm{a}}$
}

Objective: Our objective was to analyze the results of transapical aortic valve implantation in high-risk patients with aortic stenosis at up to 3 years after the procedure.

\begin{abstract}
Methods: A total of 299 patients underwent transapical aortic valve implantation from February 2006 until January 2010 using the Edwards SAPIEN transcatheter xenograft. Mean patient age was $82 \pm 6$ years and 70\% were female. Logistic EuroSCORE and Society of Thoracic Surgeons score predicted risks for mortality were $31 \% \pm 16 \%$ and $12 \% \pm 8 \%$, respectively. All patients were treated in a hybrid operative theater by a team of anesthetists, cardiologists and cardiac surgeons.
\end{abstract}

Results: Successful valve implantation was performed in all patients. Transapical aortic valve implantation was uneventful in 267 patients $(89.3 \%)$, whereas 32 patients $(10.7 \%)$ required additional interventions. Such interventions included cardiopulmonary bypass support in 18, implantation of a second SAPIEN valve in 15, coronary intervention in 9 , conversion to conventional surgery in 6 , and annulus perforation in 3 patients (not mutually exclusive). Intraprocedural stroke was not observed in any patient, although $2(0.7 \%)$ patients had a delayed stroke during their hospital stay. Overall survival was $91 \%$ at 30 days, $73 \%$ at 1 year, $68 \%$ at 2 years, and $58 \%$ at 3 years.

Conclusions: Transapical aortic valve implantation can be performed with good outcomes in high-risk patients with aortic stenosis. Perioperative complications occur in approximately $10 \%$ of patients, and a variety of interventions are required for these events. We believe a team approach is therefore essential for the success of transapical aortic valve implantation (J Thorac Cardiovasc Surg 2012;143:326-31)

Conventional aortic valve replacement (AVR) is a standardized procedure with very good outcomes in patients with aortic stenosis (AS). ${ }^{1-3}$ Over time, however, patients requiring AVR have been increasing in age with an increasing number of comorbidities. Parallel to this trend, transcatheter $(\mathrm{T})$ aortic valve implantation (AVI) techniques have been developed for minimally invasive therapy. T-AVI is currently being recommended for elderly high-risk patients only. ${ }^{4}$ After CE approval in 2008, these procedures are gaining increasing acceptance in Europe. For example, transapical (TA) AVI is being performed in more than $50 \%$ of all German cardiac surgical centers.

For T-AVI a retrograde transfemoral (TF) or an antegrade TA approach is available. ${ }^{5-11}$ The CoreValve prosthesis (Medtronic, Inc, Minneapolis, Minn) is being used for TF implantations and the SAPIEN prosthesis (Edwards Lifesciences, Inc, Irvine, Calif) for TF and TA implantations. There is no randomized clinical trial comparing clinical

From the Departments of Cardiac Surgery, ${ }^{\mathrm{a}}$ Cardiology, ${ }^{\mathrm{b}}$ and Anaesthesia, ${ }^{\mathrm{c}}$ University Leipzig, Heart Center, Leipzig, Germany.

Disclosures: Authors have nothing to disclose with regard to commercial support.

Received for publication May 24, 2010; revisions received Oct 5, 2010; accepted for publication Oct 20, 2010; available ahead of print July 4, 2011.

Address for reprints: Thomas Walther, MD, PhD, Kerckhoff Klinik Heart Center, Department Cardiac Surgery, Benekestrasse 2-8, D-61231 Bad Nauheim, Germany (E-mail: t.walther@kerckhoff-klinik.de).

$0022-5223 / \$ 36.00$

Copyright $($ C 2012 by The American Association for Thoracic Surgery doi: $10.1016 /$ j.jtcvs.2010.10.063 results using the TF and the TA approaches at present; thus the superiority or inferiority of these approaches has not yet been proven. In addition, large-volume single-center results as well as intermediate-term outcome of TA-AVI have not yet been reported. The aim of our study was therefore to analyze the outcomes of TA-AVI in a large number of consecutive patients, as well as to characterize the follow-up status at up to 3 years after the procedure.

\section{METHODS}

From February 2006 until January 2010, a total of 299 patients underwent TA-AVI using the Edwards SAPIEN transcatheter xenograft. All patients gave written informed consent and the study was approved by the institutional ethics review board. Elderly patients with severe AS and a high risk profile (additive EuroSCORE $\geq 9$ ) or known risk factors for conventional surgery such as a porcelain aorta, chest radiation, previous cardiac surgery, or previous mediastinitis underwent the screening protocol for T-AVI. Such screening started with transesophageal echocardiography to measure the aortic annulus diameter and determine the pattern of leaflet calcification, as well as to exclude any other significant valve dysfunction. A minimum device oversizing of $1 \mathrm{~mm}$ in exceptional cases (ie, patients at very high risk for conventional surgery with a "borderline" annulus diameter) and $2 \mathrm{~mm}$ in all other patients was required. Cardiac catheterization was performed to exclude coronary artery disease. Patients with suspicion of a short aortic annulus to coronary artery distance on cardiac catheterization underwent additional computed tomographic visualization of the aortic root to more accurately determine this distance. In addition, pulmonary function testing and carotid duplex studies were performed routinely in all patients. All patients who were referred to our department with symptomatic AS that fulfilled the abovementioned risk criteria were screened for potential TA-AVI. Patients were discussed by the transcatheter valve team, consisting of cardiologists and cardiac surgeons, before the implantation 


$$
\begin{aligned}
& \text { Abbreviations and Acronyms } \\
& \begin{aligned}
\text { AVI } & =\text { aortic valve implantation } \\
\text { AS } & =\text { aortic stenosis } \\
\text { AVR } & =\text { aortic valve replacement } \\
\text { CPB } & =\text { cardiopulmonary bypass } \\
\text { FEV } & =\text { functional expiratory volume in } 1 \text { second } \\
\text { STS } & =\text { Society of Thoracic Surgeons } \\
\text { T-AVI } & =\text { transcatheter aortic valve implantation } \\
\text { TA } & =\text { transapical } \\
\text { TF } & =\text { transfemoral }
\end{aligned}
\end{aligned}
$$

was scheduled. However, patients who were referred directly to our cardiology department were investigated with a "TF first" intention whereas those who were referred directly to our cardiac surgery department were investigated with a "TA first" approach. Patient-specific factors were also considered when deciding on the procedural approach. For example, patients with severe peripheral vascular disease or small femoral arteries ( $<7 \mathrm{~mm}$ in diameter) were preferentially treated with TA-AVI and patients with severe respiratory dysfunction (functional expiratory volume in $1 \mathrm{sec}-$ ond $\left[\mathrm{FEV}_{1}\right]<50 \%$ of predicted) were preferentially treated with TF-AVI. TA-AVI was performed in a hybrid operative theater by a team of cardiac anesthetists, cardiologists, and cardiac surgeons in a standard fashion as described previously. ${ }^{12}$ Heparin (100 IU/kg) was administered during the procedure to achieve an activated clotting time of 300 seconds. Transthoracic echocardiography was performed before discharge in all patients and at yearly intervals thereafter in the majority of patients. Follow-up consisted of mail and/or telephone interview of patients and/or their family members and was supplemented by information from the patients' cardiologists and/or family physicians. Postoperative medication consisted of aspirin $(100 \mathrm{mg} / \mathrm{d})$ only in patients who were in sinus rhythm and of additional clopidogrel or warfarin treatment if required for other indications, for example, stent placement or chronic atrial fibrillation.

During the study period of 4 years, a total of 1700 patients underwent isolated conventional AVR at our center. The annual number of isolated AVR procedures increased slightly over the study period, in parallel with the increasing number of T-AVI procedures. Approximately 700 highrisk patients were entered into the screening process for T-AVI, and approximately half of those patients were treated with TF-AVI and the other half with TA-AVI.

\section{STATISTICAL ANALYSIS}

Continuous variables are expressed as mean \pm standard deviation for those variables with a gaussian distribution or as median values only for nonnormally distributed data. Categorical data are expressed as proportions. Independent continuous variables were compared by the 2-tailed Student $t$ test or Mann-Whitney $U$ test as appropriate. Cumulative survival was calculated by Kaplan-Meier methods with $95 \%$ confidence limits. Statistical calculations were performed using the 17.0 SPSS (SPSS, Inc, Chicago, Ill) and Microsoft Excel 2007 (Microsoft, Redmond, Wash) software packages.

\section{RESULTS}

A total of 299 patients received TA-AVI during the study period. The mean age was $82.1 \pm 6.4$ years and 209 patients
TABLE 1. Preoperative patient characteristics

\begin{tabular}{lc}
\hline \multicolumn{1}{c}{$\mathbf{N}$} & $\mathbf{2 9 9}$ \\
\hline Age (y) & $82.1 \pm 6.4$ \\
Female (n/\%) & $209(70 \%)$ \\
Ejection fraction & $55 \pm 14$ \\
Prior CVA/TIA & $56(18.7 \%)$ \\
Pulmonary hypertension & $80(26.8 \%)$ \\
Previous cardiac surgery & $84(28.1 \%)$ \\
Peripheral vascular disease & $141(47.2 \%)$ \\
Porcelain aorta & $39(13 \%)$ \\
Chronic pulmonary disease & $129(43.1 \%)$ \\
$\quad$ FEV & $<50 \%$ of normal \\
$\quad$ FEV & $50 \%-70 \%$ of normal \\
$\quad$ VC $<50 \%$ of normal & $18(6 \%)$ \\
$\quad$ VC $50 \%-70 \%$ of normal & $50(16.7 \%)$ \\
Creatinine $>200 \mu$ mol/L & $25(8.4 \%)$ \\
Chronic dialysis & $63(21.1 \%)$ \\
\hline
\end{tabular}

$C V A$, Cerebrocascular accident; TIA, transitory ischemic attack; $F E V_{l}$, functional expiratory capacity in 1 second; $V C$, vital capacity.

$(70 \%)$ were female. Additive EuroSCORE predicted risk of mortality was $11.8 \pm 2.2$, logistic EuroSCORE was $31 \% \pm$ $16 \%$, and Society of Thoracic Surgeons (STS) score was $12 \% \pm 8 \%$. Preoperative New York Heart Association functional status was II in $49(16.4 \%)$, III in 199 $(66.6 \%)$, and IV in $51(17 \%)$ patients. Data on preoperative patient characteristics are supplied in Table 1. Perioperative and follow-up outcome data are displayed in Table 2.

Stroke occurred in 2 patients during the in-hospital stay. Both were extubated initially without any symptoms or lateralizing neurologic signs, but then sudden incomplete hemiparesis developed on postoperative day 1. Functional recovery was good in both patients. During the overall follow-up period, another 3 patients had a stroke. Temporary renal replacement therapy (continuous venovenous hemodialysis or dialysis) was required in $15 \%$ of patients

TABLE 2. Perioperative parameters and outcomes

\begin{tabular}{lc}
\hline \multicolumn{1}{c}{$\mathbf{N}$} & $\mathbf{2 9 9}$ \\
\hline Logistic EuroSCORE & $31 \% \pm 15.8 \%$ \\
STS score & $12 \% \pm 7.7 \%$ \\
Thirty-day mortality & $8.7 \%$ \\
Annulus diameter & $22.7 \pm 1.5 \mathrm{~mm}$ \\
SAPIEN valve diameter & $25.2 \pm 1.5 \mathrm{~mm}$ \\
Surgical bleeding & \\
$\quad$ Chest wall & $1 \%(\mathrm{n}=3)$ \\
$\quad$ Left ventricular apex & $1 \%(\mathrm{n}=3)$ \\
Conversion to sternotomy and conventional AVR & $2 \%(\mathrm{n}=6)$ \\
Contrast dye & $99 \pm 64 \mathrm{~mL}$ \\
Endocarditis & $0.4 \%(\mathrm{n}=1)$ \\
Perioperative stroke & $0.7 \%(\mathrm{n}=2)$ \\
Reoperation for $>$ moderate AI & $0.7 \%(\mathrm{n}=2)$ \\
New onset pacemaker implantation & $4 \%(\mathrm{n}=12)$ \\
\hline STS, Society Thoracic Surgeons; AVR, aortic valve replacement; $A I$, aortic \\
incompetence.
\end{tabular}


TABLE 3. Patient outcomes in relation to the logistic EuroSCORE

\begin{tabular}{lccc}
\hline \multicolumn{1}{c}{ Logistic EuroSCORE } & $<\mathbf{2 0} \%$ & $\mathbf{2 0} \%-\mathbf{4 0} \%$ & $>\mathbf{4 0} \%$ \\
\hline $\mathrm{N}$ & 80 & 142 & 77 \\
Mean logistic EuroSCORE & $15 \%$ & $29 \%$ & $53 \%$ \\
Mean STS score & $9 \%$ & $12 \%$ & $17 \%$ \\
Thirty-day mortality & $5 \%$ & $9.8 \%$ & $10.4 \%$ \\
Follow-up mortality & $22 \%$ & $25 \%$ & $39 \%$ \\
\hline
\end{tabular}

STS, Society Thoracic Surgeons.

postoperatively. These 45 patients had a preoperative creatinine concentration of $2.1 \mathrm{mg} / \mathrm{dL}$ in comparison with $1.1 \mathrm{mg} / \mathrm{dL}$ for all other patients $(P<.001)$.

Cardiopulmonary bypass (CPB) was used by intention in 10 patients at the beginning of the study. Thereafter, only femoral guidewires were placed in patients as a "safety net." A total of $18(6.3 \%)$ of 289 patients had to be converted to $\mathrm{CPB}$ owing to hemodynamic instability, coronary ischemia, annular tear, valve dysfunction requiring valvein-valve implantation, apical bleeding, or conversion to conventional AVR surgery. The logistic EuroSCORE $(34 \%)$ and STS score $(16.7 \%)$ were higher in patients who required CPB conversion than in the remaining patients, and the 30-day mortality was significantly elevated (44\% compared with $6.6 \%, P=.01$ ).

More specifically, the following complications occurred:

A. Coronary ischemia in $9(3 \%)$ patients owing to coronary occlusion $(\mathrm{n}=1)$, impingement $(\mathrm{n}=7)$, or thrombosis $(n=1)$

B. Requirement for the implantation of a second SAPIEN valve in $15(5 \%)$ patients owing to low positioning $(\mathrm{n}=7)$, leaflet dysfunction $(\mathrm{n}=5)$, ventricular septal defect $(n=2)$, or upside down valve positioning $(n=1)$

C. Annulus perforation in $3(1 \%)$ patients

CPB had to be used in $66 \%$ (A), 20\% (B), and 100\% (C) of these patients, and corresponding 30-day mortality was $44 \%$ (A), $27 \%$ (B), and 33\% (C).

A total of $32(10.7 \%)$ patients had 1 or more perioperative complications, whereas $267(89.3 \%)$ patients had an

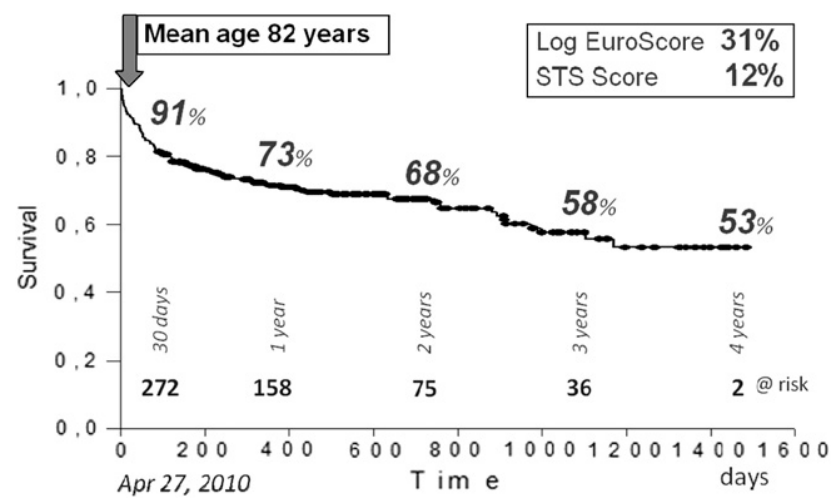

FIGURE 1. Overall survival. STS, Society of Thoracic Surgeons.
TABLE 4. Causes of death

\begin{tabular}{lcc}
\hline & $\begin{array}{c}\text { Thirty-day } \\
\text { in-hospital }\end{array}$ & Follow-up \\
\hline Cardiac_circulatory & $53 \%$ & $35 \%$ \\
$\quad$ (LCOS, infarction, SCD, ...) & & \\
Respiratory (failure, pneumonia, & $23 \%$ & $21 \%$ \\
$\quad$ pulmonary embolism, ...) & $12 \%$ & $19 \%$ \\
MSOF, sepsis & $8 \%$ & $4 \%$ \\
Abdominal + cancer & - & $3 \%$ \\
Stroke, cerebral bleeding & $4 \%$ & $18 \%$ \\
Other (unclear, embolism, vasculitis, ...) & & \\
\hline
\end{tabular}

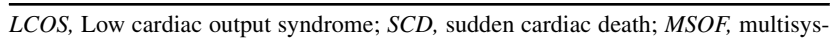
tem organ failure.

uneventful valve implantation. Logistic EuroSCORE was $35 \%$ versus $31 \%$, STS score $14 \%$ versus $11.7 \%$, and $30-$ day mortality was $31 \%$ versus $6 \%$ in these 2 groups, respectively.

Patient survival in relation to different logistic EuroSCORE subcategories $(<20 \%, 20 \%-40 \%$, and $>40 \%)$ is displayed in Table 3. Overall survival is displayed in Figure 1. Thirty-day mortality for the entire group was $8.7 \%$. However, 30 -day mortality $(17 / 150,11.3 \%)$ was lower for the first half of the patients (log EuroSCORE, $29.3 \%$; STS score, $13.5 \%$ ) than it was for the second half of the patients $(9 / 149,6 \%$ ) (log EuroSCORE, 33.3\%; STS score, $11.3 \% ; P=.053)$. There was no significant change in patient risk profile during the study period.

Total mortality during the follow-up interval of 487 days (range, 3 months to 4 years) was $28 \%$. Causes of death are displayed in Table 4.

Echocardiographic results are supplied in Table 5. No patient had structural valve degeneration during the current follow-up period.

Mitral valve incompetence was absent in $7 \%$, mild in $61 \%$, moderate in $30 \%$, and severe in $2 \%$ of patients preoperatively. During postoperative echocardiographic examination, there was an overall improvement in mitral incompetence (absent in $23 \%$, mild in $56 \%$, moderate in $21 \%$, and severe in none). Mortality at 30 days was $6 \%$ for patients with no or mild preoperative mitral incompetence and $20 \%$ for those with moderate or severe mitral

TABLE 5. Echocardiographic results

\begin{tabular}{lcccc}
\hline \multicolumn{1}{c}{$\mathbf{n}$} & $\begin{array}{c}\text { Discharge } \\
(\mathbf{2 5 6})\end{array}$ & $\begin{array}{c}\text { One year } \\
(\mathbf{8 0})\end{array}$ & $\begin{array}{c}\text { Two years } \\
\mathbf{( 4 3 )}\end{array}$ & $\begin{array}{c}\text { Three years } \\
(\mathbf{1 9})\end{array}$ \\
\hline $\mathrm{V}_{\max }(\mathrm{m} / \mathrm{s})$ & 1.9 & 2 & 1.9 & 2.1 \\
$\mathrm{P}_{\max }(\mathrm{mm} \mathrm{Hg})$ & 12 & 11 & 12 & 13 \\
$\mathrm{P}_{\text {mean }}(\mathrm{mm} \mathrm{Hg})$ & 8 & 5 & 5 & 6 \\
$\mathrm{EF}(\%)$ & 56 & 58 & 58 & 59 \\
$\mathrm{AI}$ & & & & \\
$\quad$ Mild (first degree) & $37 \%$ & $54 \%$ & $53 \%$ & $47 \%$ \\
$\quad$ Moderate & $4 \%$ & $4 \%$ & $5 \%$ & $5 \%$ \\
\hline
\end{tabular}

$V_{\max }$, Maximum transvalvular blood flow velocity; $P_{\max }$ maximum transvalvular pressure gradient; $E F$, ejection fraction; $A I$, aortic incompetence. 
incompetence. The effect of respiratory function on postoperative outcome was also assessed. Preoperative $\mathrm{FEV}_{1}$ and vital capacity were $98 \%$ and $84 \%$ of normal in patients who survived the procedure versus $85 \%$ and $68 \%$ in those who died within 30 days $(P<.01)$. Patients who died during follow-up had a preoperative $\mathrm{FEV}_{1}$ and vital capacity of $80 \%$ and $71 \%$, respectively.

\section{DISCUSSION}

TA-AVI and TF-AVI have been established as a clinically accepted minimally invasive therapeutic option for highrisk patients with AS in several centers across Europe. Current literature results indicate a 30-day mortality rate in the range of $10 \%$ for patients with higher risk profiles (ie, logistic EuroSCORE values between $20 \%$ and $30 \%$ ). In the absence of a randomized clinical trial comparing the TF and TA approaches, it is currently unknown which procedure offers a better alternative for patients. Despite this fact, a "TF-first" strategy, whereby a TF approach is the default procedure and TA-AVI is only offered in the presence of severe peripheral vascular disease, has become the clinical norm at most sites. We herein report our results of 299 consecutive high-risk patients with AS receiving TA-AVI by an interdisciplinary team in a hybrid operative theater over 4 years. During this time period, a similar number of patients underwent TF-AVI by the same team. Indications for TAAVI, although mostly based on patient referral patterns, were in part directed by anatomic reasons. Of note, peripheral vascular disease was present in $47 \%$ of our TA-AVI patients, a proportion that is quite comparable with other series in the literature. Our overall results were quite positive, particularly inasmuch as the current series includes the early learning experience with TA-AVI. High-risk patients with AS, presenting with a mean logistic EuroSCORE of $31 \%$ and an STS score of $12 \%$, successfully underwent minimally invasive treatment usually without CPB support. Our observed 30-day mortality rate was acceptable in view of the high-risk profile of our patients. Several series in the literature have reported similar mortality rates in lower-risk patients. When estimating risk for patients undergoing aortic valve surgery, the STS score should always be considered foremost inasmuch as the logistic EuroSCORE is known to lead to an overestimation of the effective risk. ${ }^{13,14}$ Alternatively, the logistic EuroSCORE can be divided by 3 , which would lead to a mean predicted risk of mortality of $10.5 \%$ in the current series, to get a more realistic estimate on a patient's individual risk. Our observed stroke risk was much lower than those reported for TFAVI, most likely owing to minimal manipulations of the aortic arch when using the antegrade TA approach. Similarly, several reports on T-AVI in the literature have displayed a very low or absent stroke rate, all of which were performed using an antegrade TA approach. ${ }^{8,9,11,15}$ Patient inclusion criteria were consistently applied throughout the current study and only patients at high risk for conventional AVR were included, in agreement with recent recommendations. ${ }^{4}$ This is owing to the fact that conventional AVR yields excellent results in regular risk patients of almost any age,${ }^{1-3}$ as well as our observations that unexpected, sudden, and occasionally life-threatening complications can occur during all T-AVI procedures. Such complications have led us to develop specific therapeutic approaches, as described previously. ${ }^{12}$ These prophylactic and therapeutic measures include temporary hemodynamic support using inotropes to avoid hypotension in patients with hypertrophic ventricles, the placement of femoral guidewires to be able to gain CPB access easily and rapidly in case of severe hemodynaymic compromise, percutaneous coronary intervention to treat coronary artery impingement, as well as valve-in-valve implantation in the case of malposition and/or malfunction of the initial prosthesis. As indicated in Table 2, such complications occurred in a minority of patients. However, they occurred throughout the entire study period and were not completely avoidable or foreseeable. We can conclude from our experience that the surgical team should be prepared for such complications to occur at any time and to have a well thought out backup plan to deal with such complications. Annular perforation was a particularly troublesome complication that occurred in 3 $(1 \%)$ patients. On the basis of this limited experience, identification of specific risk factors for this complication may be difficult. Excessive calcification of the aortic valve cusps and the aortic annulus together with mitral annular calcification leading to reduced elasticity of the aortic root may have been a contributing factor. We suggest that moderate oversizing of 1 to $2 \mathrm{~mm}$ should be applied in such cases and that aggressive oversizing be avoided. Treatment of an annular perforation can be successfully performed with conventional AVR surgery and patch closure of the defect. In contrast, occurrence of a small ventricular septal defect, most certainly owing to calcium penetrating the membranous septum, can be successfully treated by valve-in- valve implantation (ie, a second SAPIEN prosthesis inside the first one). The team approach in a hybrid operative theater allowed us to standardize the procedure leading to short operative times of approximately 1 hour, as well as a relatively low amount of administered contrast dye. Availability of $\mathrm{CPB}$, however, will remain a cornerstone of T-AVI therapy in all patients for the foreseeable future. Respiratory dysfunction was strongly associated with decreased survival in the current series. As such, respiratory dysfunction may not be weighed sufficiently with current EuroSCORE risk assessment. Our clinical experience with TF-AVI, however, has also been somewhat disappointing in these challenging patients. Causes of death as shown in Table 4 were mostly cardiac, respiratory, and abdominal, as expected for an elderly high-risk population. Unknown causes of death were also present in several patients during follow-up, 
predominantly because of the high rate of comorbidities and the low autopsy rate in elderly patients. When evaluating the overall survival of our patient group, one must consider that the mean patient age was 82 years at the time of valve implantation. Although natural attrition will play a significant role when evaluating postprocedure survival in T-AVI patients, we believe that 1-year survival should be used as an important clinical end point.

Risk subgroup analysis revealed that the logistic EuroSCORE as well as the STS score were able to predict patient outcome relatively well, as shown in Table 3. Patients with a lower risk score had improved perioperative and followup survival. One may conclude from this observation that lower-risk patients with AS should be treated with TAAVI. It must be kept in mind, however, that conventional AVR is associated with very low operative risk and excellent long-term outcomes in such patients. Furthermore, the high costs of transcatheter valves may not be justified in lower-risk patients. As mentioned previously, we have learned that complications can occur any time during TAAVI and can usually be handled with a predefined therapeutic strategy. Nevertheless, mortality is significantly higher in patients who had a procedural complication. Therefore, utmost attention should be given to precise valve size selection, implantation procedural access, and valve positioning to obtain an optimal outcome. Despite potential procedural complications, we observed an improvement in outcomes over time. For the second half of patients in the current study, 30-day mortality was reduced to $6 \%$ in a patient population with a similar risk score to the first half. We believe this improvement is due to a learning effect, combined with the fact that we were able to perform these procedures without interruptions, as has occurred in other studies. ${ }^{16}$ Hemodynamic function of the SAPIEN valve was excellent, as indicated by low blood flow velocities and low pressure gradients during echocardiographic examination (Table 5). Left ventricular ejection fraction was well preserved during follow-up. We can therefore conclude that the apical access, as expected, does not lead to any ventricular compromise. The excellent hemodynamic performance for such transcatheter valves, however, is tempered by the increased risk of paravalvular leakage. A paravalvular leak was present in more than $40 \%$ of patients in the current study. Fortunately, paravalvular incompetence was mild in the vast majority of our patients, and only 2 patients required reoperation for increasing aortic incompetence 6 weeks after the procedure. In addition, clinically relevant hemolysis was not observed in any patient. This observation may have been due to the fact that the SAPIEN valve does not have a sewing ring, thereby avoiding cellular trauma that occurs when a regurgitant jet comes into contact with a rigid sewing ring. Treatment of younger and more physically active patients in the future, however, will require devices that are able to achieve a better seal with the annulus and thus avoid paravalvular leakage. Optimal imaging is the key for successful T-AVI. Valve positioning should be performed exactly intra-annular, but subcoronary. Valve implantation is best performed under high-quality fluoroscopic and transesophageal echocardiographic control. We recommend positioning of the SAPIEN valve with approximately $40 \%$ of the stent above and $60 \%$ below the native annulus, although Edwards recommends a 50/50 distribution. It must be kept in mind, however, that the aortic annulus is scalloped and not planar and that the potential motion and future position of the native calcified leaflets during valve implantation are difficult to predict before deployment. Our recommendation on the height of implantation is based on the need to avoid any coronary artery compromise. Advanced imaging modalities such as perioperative 3-dimensional reconstruction with online overlay visualization using the DynaCT technique (Siemens Inc, Forchheim, Germany) may lead to better imaging quality and thus an improved safety margin for the patients. ${ }^{17}$

The current study has several limitations, most importantly the relatively short follow-up period. More detailed analysis of potential risk factors will have to be performed from larger multicenter series to better identify ideal criteria for T-AVI therapy. Further technological improvements, by means of enhanced imaging as well as improved valve prostheses and delivery catheters, will also need to be investigated to determine whether further improvements can be achieved.

In summary, TA-AVI has evolved as an imminently feasible minimally invasive therapeutic option for highrisk patients with AS. Our experiences with the initial 299 patients over a 4-year period have led to an improvement in outcomes over time. However, sudden and unpredictable complications can occur at any time during T-AVI therapy. We therefore recommend that such procedures be performed in a hybrid operative theater by an experienced team of anesthetists, cardiologists, perfusionists, and cardiac surgeons.

\section{References}

1. Gummert JF, Funkat A, Beckmann A, Schiller W, Hekmat K, Ernst M, et al. Cardiac surgery in Germany during 2008. A report on behalf of the German Society for Thoracic and Cardiovascular Surgery. Thorac Cardiovasc Surg. 2009;57: 315-23.

2. Kolh P, Kerzmann A, Honore C, Comte L, Limet R. Aortic valve surgery in octogenarians: predictive factors for operative and long term results. Eur J Cardiothorac Surg. 2007;31:600-6.

3. Melby SJ, Zierer A, Kaiser SP, Guthrie TJ, Keune JD, Schuessler RB, et al. Aortic valve replacement in octogenarians: risk factors for early and late mortality. Ann Thorac Surg. 2007;83:1651-7.

4. Vahanian A, Alfieri O, Al-Attar N, Antunes M, Bax J, Cormier B, et al. European Association of Cardio-Thoracic Surgery; European Society of Cardiology; European Association of Percutaneous Cardiovascular Interventions: Transcatheter valve implantation for patients with aortic stenosis: a position statement from the European Association of Cardio-Thoracic Surgery (EACTS) and the European Society of Cardiology (ESC), in collaboration the European Association of Percutaneous Cardiovascular Interventions (EAPCI). Eur Heart J. 2008;11:1463-70.

5. Cribier A, Eltchaninoff H, Bash A, Borenstein N, Tron C, Bauer F, et al. Percutaneous transcatheter implantation of an aortic valve prosthesis for calcific aortic stenosis: first human case description. Circulation. 2002;106:3006-8. 
6. Webb JG, Chandavimol M, Thompson CR, Ricci DR, Carere RG, Munt BI, et al. Percutaneous aortic valve implantation retrograde from the femoral artery. Circulation. 2006;113:842-50.

7. Grube E, Laborde JC, Gerckens U, Felderhoff T, Sauren B, Buellesfeld L, et al. Percutaneous implantation of the CoreValve self-expanding valve prosthesis in high risk patients with aortic valve disease: the Siegburg first-in-man study. Circulation. 2006; 114:1616-24

8. Lichtenstein SV, Cheung A, Ye J, Thompson CR, Carere RG, Pasupati S, et al. Transapical transcatheter aortic valve implantation in humans: initial clinical experience. Circulation. 2006;114:591-6.

9. Walther T, Falk V, Borger MA, Dewey T, Wimmer-Greinecker G, Schuler G, et al. Minimally invasive transapical beating heart aortic valve implantation-proof of concept. Eur J Cardiothorac Surg. 2007;31:9-15.

10. Webb JG, Pasupati S, Humphries K, Thompson C, Altwegg L, Moss R, et al. Percutaneous transarterial aortic valve replacement in selected high-risk patients with aortic stenosis. Circulation. 2007;116:755-63.

11. Walther T, Simon P, Dewey T, Wimmer-Greinecker G, Falk V, Kasimir MT, et al. Transapical minimally invasive aortic valve implantation: multicenter experience. Circulation. 2007;116(11 Suppl):I240-5.
12. Walther T, Dewey T, Borger MA, Kempfert J, Linke A, Becht R, et al. Transapical aortic valve implantation: step by step. Ann Thorac Surg. 2009;87:276-83.

13. Dewey TM, Brown D, Ryan WH, Herbert MA, Prince SL, Mack MJ. Reliability of risk algorithms in predicting early and late operative outcomes in high-risk patients undergoing aortic valve replacement. J Thorac Cardiovasc Surg. 2008;135:180-7.

14. Gummert JF, Funkat A, Osswald B, Beckmann A, Schiller W, Krian A, et al. EuroSCORE overestimates the risk of cardiac surgery: results from the national registry of the German Society of Thoracic and Cardiovascular Surgery. Clin Res Cardiol. 2009;98:363-9.

15. Bleiziffer S, Ruge H, Mazzitelli D, Hutter A, Opitz A, Bauernschmitt R, et al. Survival after transapical and transfemoral aortic valve implantation: talking about two different patient populations. J Thorac Cardiovasc Surg. 2009;138 1073-80.

16. Svensson LG, Dewey T, Kapadia S, Roselli EE, Stewart A, Williams M, et al. United States feasibility study of transcatheter insertion of a stented aortic valve by the left ventricular apex. Ann Thorac Surg. 2008;86:46-54.

17. Kempfert J, Falk V, Schuler G, Linke A, Merk D, Mohr FW, et al. Dyna-CT during minimally invasive off-pump transapical aortic valve implantation. Ann Thorac Surg. 2009;88:2041. 